\title{
Benamingen van dieren in de Nederlandse en in de Tsjechische vaste adjectivische vergelijkingen in de spiegel van de geschreven corpora
}

\begin{abstract}
Animal names or zooappellatives constitute an important part of the idioms and proverbs in the majority of natural languages. The Dutch idioms with an animal element were described from various perspectives by Kowalska-Szubert (1996). The Czech idioms with animal names were the subject of various studies carried out e.g. by Mrhačová (Mrhačová et al. 2000, Mrhačová-Kouptsevitch 2004). In this article we compare by the means of corpus research the use of animal names in the adjectivebased similes in the current written Dutch and in the current written Czech. This research is based on the excerpta of the largest written corpora available for the Dutch and the Czech, namely the Corpus Contemporary Dutch and the Corpus Contemporary Czech SYN version 5.
\end{abstract}

Keywords: similes, animal names, Czech, Dutch, Corpus Hedendaags Nederlands, Czech National Corpus, frequency

\section{Inleiding}

Benamingen van dieren of zooappellativa maken in belangrijke mate deel uit van vaste verbindingen en spreekwoorden in de meeste natuurlijke talen. Omdat mensen van oudsher met dieren samenleven en er veel ervaring mee hebben opgedaan, zijn verschillende elementen van het dierenrijk ook in de menselijke beeldspraak opgenomen. Nederlandse vaste verbindingen met een dierelement werden uit verschillende gezichtspunten beschreven door Agata Kowalska-Szubert (1996). Tsjechische vaste verbindingen met benamingen van dieren zijn bijv. door Eva Mrhačová onder de loep genomen (verg. Mrhačová e.a. 2000, Mrhačová \& Kouptsevitch 2004). Nederlandse en Tsjechische vaste verbindingen met een dierelement werden in het kader van een bachelor- of masterscriptie bijv. door Buršíková (2006) of Krátká (2008) vergeleken. Aan Tsjechische vaste vergelijkingen is het eerste deel van het fraseologische lexicon Slovník české frazeologie a idiomatiky (Čermák e.a. 2009) gewijd, 
Nederlandse vaste vergelijkingen zijn lexicografisch verwerkt in verschillende Nederlandse fraseologische woordenboeken (zie bijv. Groot e.a. 1999).

In dit artikel proberen we het gebruik van zooappellativa in vaste adjectivische vergelijkingen in het huidige geschreven Nederlands en in het huidige geschreven Tsjechisch te vergelijken aan de hand van een corpusonderzoek. ${ }^{1}$ Dit onderzoek is gebaseerd op excerpta uit de grootste geschreven corpora, die voor het Nederlands en het Tsjechisch beschikbaar zijn, namelijk het Corpus Hedendaags Nederlands ${ }^{2}$ en het corpus hedendaags Tsjechisch SYN versie $5 .{ }^{3}$

\section{Doelstelingen van het corpusonderzoek en de hypotheses}

In ons corpusonderzoek hebben we ons geconcentreerd op de vaste vergelijkingen waarin een zooappellativum als comparatum en een adjectief als tertium comparationis voorkomen, bijv. (zo) gezond als een vis - zdravý jako rybička.

In het kader van het corpusonderzoek werden antwoorden op de volgende vragen gezocht:

1.Welke vaste adjectivische vergelijkingen met benamingen van dieren worden in het huidige geschreven Nederlands en in het huidige geschreven Tsjechisch volgens de gegevens uit de geschreven corpora het vaakst gebruikt?

2 . Welke benamingen van dieren verschijnen het vaakst als comparata in deze vaste adjectivische vergelijkingen?

3. Worden de benamingen van dieren, die als comparata in de vaste adjectivische vergelijkingen het vaakst verschijnen, in beide talen met dezelfde eigenschappen geassocieerd?

4. Welke andere overeenkomsten en/of verschillen tussen Nederlandse en Tsjechische adjectivische vergelijkingen met een dierelement weerspiegelen zich in de geschreven corpora?

We zijn uitgegaan van de veronderstelling dat het Nederlands en het Tsjechisch over enkele gelijke vaste adjectivische vergelijkingen met hetzelfde dierenelement beschikken, maar dat de frequentie van deze congruente vaste vergelijkingen mogelijk verschillend kan zijn. We hebben ook verondersteld dat

${ }^{1}$ Deze bijdrage kwam tot stand dankzij de ondersteuning verleend voor specifiek universitair onderzoek in 2016 an Univerzita Palackého te Olomouc door het Ministerie van Onderwijs, Jeugd- en Sportzaken van de Tsjechische Republiek in het kader van het project IGA_FF_2016_029 Akademický úvod do nizozemské filologie se zaměřním na lingvistiku.

2 De bètaversie van het Corpus Hedendaags Nederlands kan geraadpleegd worden via de website http://chn.inl.nl/. Nadere informatie over dit corpus is te vinden op de website van het Instituut voor de Nederlandse Taal http://www.inl.nl/taalmaterialen.

${ }^{3}$ Het corpus SYN versie 5 is raadpleegbaar op de website van het Tsjechische Nationale Corpus http://www.korpus.cz. De karakteristiek van het corpus zie http://wiki.korpus.cz/doku.php/ en:cnk:syn:verze5. 
de Tsjechische en Nederlandse benamingen voor dieren - op een paar uitzonderingen na - met dezelfde eigenschappen geassocieerd worden en dus in vergelijkingen meestal met gelijke bijvoeglijke naamwoorden voorkomen.

\section{Werkwijze}

De onderzochte vaste vergelijkingen (bijv. vrij als een vogel - volný jako pták) kenmerken zich in beide talen door een vaste, vergelijkbare structuur:

$\mathrm{ADJ}+$ als + een + SUBS in het Nederlands,

$\mathrm{ADJ}+j a k / j a k o+$ SUBS in het Tsjechisch.

De comparator wordt in het Nederlands door het voegwoord van vergelijking als uitgedrukt, in het Tsjechisch gebeurt dit door het voegwoord jak of zijn variant jako, dus door een volledig identiek equivalent. Links van de comparator staat een bijvoeglijk naamwoord (ADJ) in de functie van het tertium comparationis. Rechts van de comparator is een zelfstandig naamwoord (SUBS) in beide talen te vinden dat als comparatum dient. In het Nederlands wordt elk telbaar zelfstandig naamwoord in het enkelvoud nog door een onbepaald lidwoord een gedetermineerd - in tegenstelling tot het Tsjechisch waarin geen lidwoorden gebruikt worden.

Dankzij deze structuur kunnen adjectivische vaste verbindingen met benamingen van dieren in de geannoteerde corpora tamelijk goed opgezocht worden met behulp van de zgn. Corpus Query Language (CQL). Voor ons onderzoek hebben we de omvangrijkste synchrone geschreven corpora voor beide talen gekozen, namelijk het Corpus Hedendaags Nederlands voor het Nederlands en het corpus SYN versie 5 voor het Tsjechisch. Hoewel deze twee corpora, waarin de journalistieke teksten overheersen, niet in alle opzichten vergelijkbaar zijn (zo is het Tsjechische corpus veel groter), kunnen ze een beeld geven van de geschreven taal in een bepaalde periode. In het kader van ons onderzoek hebben we ons beperkt tot teksten die in de periode na 2000 zijn gepubliceerd. We hebben dus met subcorpora gewerkt.

Aanvankelijk werden alle adjectivische vergelijkingen met een telbaar zelfstandig naamwoord rechts van de coparator in het Corpus Hedendaags Nederlands opgezocht. ${ }^{4}$ Met behulp van de Corpus Query Language was de volgende zoekopdracht geformuleerd:

$$
\text { [pos="AA.*"] [word="als"] [word="een"][pos="N.*"] }
$$

${ }^{4}$ Om een volledige lijst met de meest gebruikte Nederlandse adjectivische vaste vergelijkigen in het huidige geschreven Nederlands te krijgen, zouden nog andere CQL-vragen gesteld moeten worden, bijv. [pos="AA.*"] [word= "als"] [pos="N."”] voor het opzoeken van de vaste als-vergelijkingen die als comparatum een niet telbaar zelfstandig naamwoord bevatten (zwart als roet, groen als gras, hard als steen). 
Vervolgens werden alle resultaten door middel van een corpusmanager op lemma gesorteerd (zie de screenshot in Afbeelding 1) en daarna handmatig geanalyseerd met het oog op het gebruik van zooappellativa in vaste vergelijkingen. ${ }^{5}$

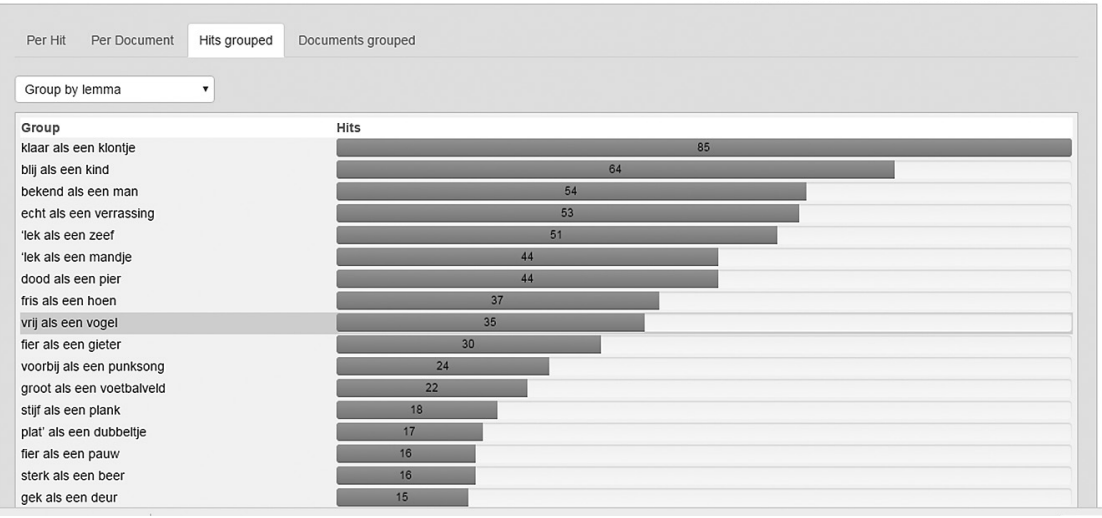

Afbeelding 1. Het opzoeken van adjectivische als-vergelijkingen in het Corpus Hedendaags Nederlands (resultaten gesorteerd op lemma)

De CQL-vraag voor het opzoeken van de adjectivische vergelijkingen in het Tsjechische corpus $S Y N$ versie 5 was: [tag="A.*"][word="jakoljak"][tag="N.*"]. Ook hier werden alle gevonden constructies met behulp van een corpusmanager gesorteerd volgens de frequentie van het lemma en vervolgens handmatig geanalyseerd met het oog op het voorkomen van verschillende zooappellativa - zie Afbeelding 2.

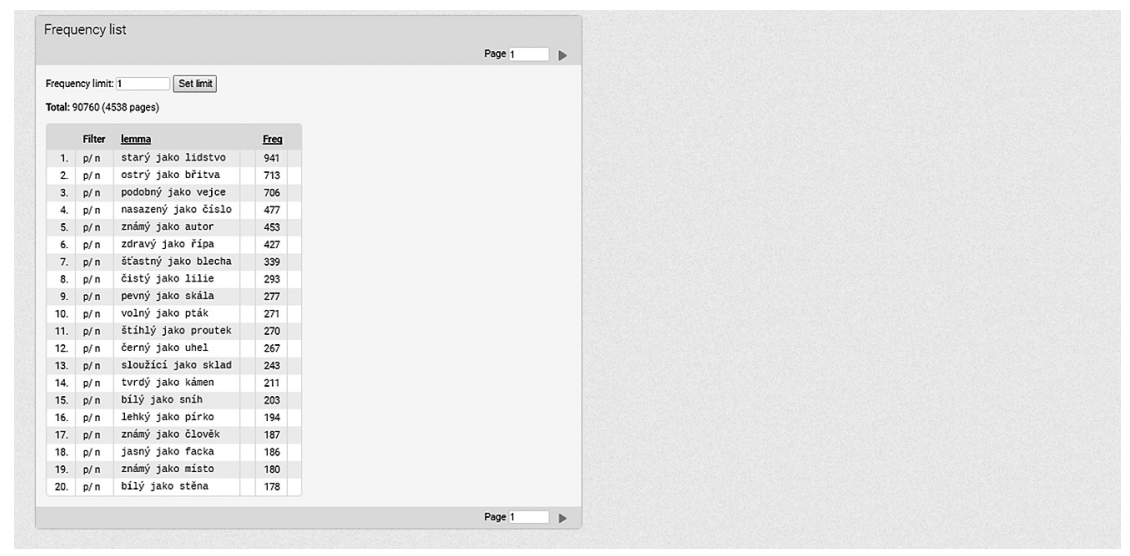

Afbeelding 2. Het opzoeken van vaste adjectivische vergelijkingen in het Tsjechische corpus SYN versie 5 (resultaten gesorteerd volgens het lemma)

${ }^{5}$ De constructies die in principe geen vaste als-vergelijkingen zijn (bijv. bekend als een man) en alle vaste adjectivische vergelijkingen zonder een dierelement (bijv. blij als een kind) zijn dus buiten beschouwing gelaten. 


\section{Resultaten van het corpusonderzoek}

Tot de vaste adjectivische vergelijkingen met een zooappellativum die volgens de gegevens uit het Corpus Hedendaags Nederlands het vaakst in het geschreven Nederlands gebruikt worden, behoren: dood als een pier, vrij als een vogel, fris 6 als een hoentje, fier/trots ${ }^{7}$ als een pauw, sterk als een beer, stoned als een garnaal, ziek als een hond, vals als een kat, gezond als een vis, koppig als een ezel. Als comparata verschijnen in deze groep niet alleen maar de gedomesticeerde zoogdieren (hond, kat, ezel), maar ook verschillende vogels (vogel, hoentje, pauw) en dieren die in het water leven (vis, garnaal).

Verder zijn in het corpus minimaal drie keer volgende vaste vergelijkingen aangetroffen: doof als een kwartel, sterk als een leeuw, glad als een aal, mak als een lammetje, sluw als een vos, gehoorzaam als een hond, groot als een paard, trots als een aap, traag als een slak, moe als een hond, koel als een kikker, lelijk als een aap.

De tien meest gebruikte Tsjechische vaste adjectivische vergelijkingen met benamingen van dieren, die in het Tsjechische corpus SYN versie 5 (in teksten van na het jaar 2000) zijn gevonden, zijn samen met de letterlijke vertaling in het Nederlands in Tabel 1 weergegeven. Op deze lijst is opvallend dat insecten (vlo, luis, bij, vlieg) als comparatum in de Tsjechische vaste vergelijkingen tamelijk vaak voorkomen. Toch zijn ook hier een paar gedomesticeerde zoogdieren (hond, lammetje, poesje) te vinden. Enkele benamingen hebben de vorm van het diminutief (visje, lammetje, bijtje).

Tabel 1. Top 10 meest gebruikte Tsjechische vaste adjectivische vergelijkingen met een zooappellativum

\begin{tabular}{|c|c|}
\hline Tsjechische vaste vergelijking & Letterlijke vertaling in het Nederlands \\
\hline št’astný jako/jak ${ }^{8}$ blecha & gelukkig als een vlo \\
\hline volný jako/jak pták & vrij als een vogel \\
\hline zdravý jako/jak rybička ${ }^{9}$ & gezond als een visje \\
\hline nervózni jako/jak pes & nerveus als een hond \\
\hline liný jako/jak veš & lui als een luis \\
\hline namačkani jako/jak sardinky & samengeperst als sardines ${ }^{10}$ \\
\hline krotký jako/jak beránek & mak als een lammetje \\
\hline pilný jako/jak včelička & ijverig als een bijtje \\
\hline slabý jako/jak moucha & zwak als een vlieg \\
\hline utahaný jako/jak kotě & moe als een poesje \\
\hline
\end{tabular}

${ }^{6}$ Soms wordt de variant fit als een hoentje gebruikt.

${ }^{7}$ Vaker verschijnt de Vlaamse variant fier als een pauw in het corpus.

${ }^{8}$ De varianten met de comparator jak worden in het Tsjechisch veel minder gebruikt dan de vergelijkingen met de comparator jako.

${ }_{9}$ Tot de tamelijk vaak gebruikte varianten van deze vergelijking behoren vergelijkingen $z d r a$ vý jako ryba (gezond als een vis) en zdravý jako rípa (gezond als een biet).

${ }^{10}$ In de betekenis: als haringen in een ton zitten. 
Opgemerkt dient hier verder te worden dat er ook verschillende varianten van de bovengenoemde vergelijkingen in het corpus $S Y N$ versie 5 gevonden zijn. Vaak wordt er nog een ander zooppellativum als comparatum gebruikt - verg. štastný jako štěně/pták/pes/kưn (gelukkig als een puppy/een vogel/een hond/ een paard), volný jako motýl/ptáček (vrij als een vlinder/een vogeltje), nervózní jako prase/sviňa (nerveus als een varken/een zwijn), líný jako prase (lui als een varken), namačkani jako herynci (samengeperst als haringen), pilný jako včela/ včelka/mravenec (ijverig als een bij/een bijtje/een mier), utahaný jako pes/kưn/ zvíre (moe als een hond/een paard/een dier). Dit correspondeert met de constatering van Mrhačová dat in de Slavische talen synoniemenrijen van vaste vergelijkingen met een dierelement vaak voorkomen: "Se synonymickými řadami se ve slovanských jazycích setkáváme jak u ustálených přirovnání vlastností (...), tak u ustálených přirovnání činností a stavů (...)" (Mrhačová-Kouptsevitch 2004: 154). [We vinden synoniemenrijen in de Slavische talen zowel bij de vaste vergelijkingen van eigenschappen als bij de vaste vergelijkingen van een handeling of van een toestand].

In het Corpus Hedendaags Nederlands werd dit verschijnsel slechts in geringe mate geobserveerd (bijv. sterk als een beer/een leeuw, trots als een pauw/ een aap $).{ }^{11}$ Synonieme bijvoeglijke naamwoorden komen als tertia comparationis in beide talen voor - verg. trots/fier als een pauw, unavený/utahaný/znavený jako pes (moe als een hond).

Op basis van de gegevens uit het Corpus Hedendaags Nederlands en het Tsjechische corpus $S Y N$ versie $5^{12}$ hebben we een lijst van de twintig vaakst voorkomende benamingen van dieren in de vaste adjectivische vergelijkingen voor beide talen samengesteld - zie Tabel 2. In deze tabel worden ook de meest voorkomende combinaties met bijvoeglijke naamwoorden bij elk zooappellativum weergegeven, dus de eigenschappen waarmee deze benamingen in de desbetreffende taal meestal geassocieerd worden. De gevallen waarin de eigenschappen in het Nederlands en in het Tsjechisch verschillend zijn, worden vet gedrukt net zoals de zooappellativa die in de andere taal geen vaste vergelijking op basis van de genoemde eigenschap vormen. Zowel de linkerkolom (Nederlands) als de rechterkolom (Tsjechisch) zijn daarbij op aflopende frequentie geordend.

11 Tot een vergelijkbare vaststelling is ook Mrhačová op basis van vergelijking van Tsjechische en Duitse de vaste verbindingen met een dierelement gekomen. Ze constateert namelijk, dat de keuze van dierenbenamingen om een bepalde betekenis in fraseologismen uit te drukken, lijkt rijker te zijn in het Tsjechisch dan in het Duits (Mrhačová et al. 2000: 42).

12 Nadat we de CQL- vraag in de vorm [tag="A.*"] [word="jakoljak"] hadden gesteld, hebben we de lemma's in de rechtse context van alle resultaten met behulp van het corpus manager op frequentie gesorteerd. Vervolgens hebben we deze lemma's handmatig geanalyseerd met het oog op de gebruikte dierenbenamingen in de vaste vergelijkingen. 
Tabel 2. Benamingen van dieren, die het vaakst als comparata in de Nederlandse en Tsjechische vaste adjectivische vergelijkingen voorkomen

\begin{tabular}{|c|c|}
\hline In het Nederlands & In het Tsjechisch \\
\hline pier-dood & $\begin{array}{l}\text { pes (hond) - nerveus, moe, trouw, woedend, gehoor- } \\
\text { zaam }\end{array}$ \\
\hline hoentje - fris, fit & $\begin{array}{l}\text { myš (muis) - bezweet, nat, arm, stil, grijs } \\
\text { kostelni myš (kerkrat) - arm }\end{array}$ \\
\hline hond-ziek, trouw, gehoorzaam, moe & blecha $($ vlo $)-$ gelukkig \\
\hline vogel/vogeltje - vrij & prase (varken) - dik, groot, lui, vies, nerveus, bezopen \\
\hline pauw - trots & pták (vogel) - vrij \\
\hline vis - gezond, fris, koud, stom & rybička/ryba (visje/vis) - gezond, levendig, fris, stom \\
\hline kat-vals, lenig & beránek (lammetje) - mak, kalm, rustig \\
\hline beer - sterk, groot & kočka (kat) - lenig, snel, slim \\
\hline aap-lelijk, trots, stoned & opice (aap) - slim, brutaal, nieuwsgierig, harig \\
\hline leeuw - sterk, dapper & kůn̆ (paard) - moe, afgemat, groot, sterk, bezweet \\
\hline garnaal - stoned & kotě (poesje) - moe, speels \\
\hline paard-groot, sterk & $l i s ̌ k a$ (vos) - slim, sluw, roodharig \\
\hline vos - sluw & kráva (koe) - groot, zwaar, bezopen \\
\hline slang - listig, verradelijk, lang & had (slang) - glad, slijmerig, lang, listig \\
\hline ezel-koppig & sardinky (sardines) - samengeperst \\
\hline kwartel-doof & $\operatorname{rak}(\mathrm{kreeft})-$ rood \\
\hline$a a l-$ glad & moucha (vlieg) - zwak \\
\hline lam/lammetje - mak & medvěd (beer) - sterk, groot, harig \\
\hline varken - vies, lui, dik & lev (leeuw) - sterk, dapper \\
\hline kreeft-rood & veš (luis) - lui \\
\hline
\end{tabular}

Hoewel meer dan de helft van de Nederlandse en Tsjechische benamingen van dieren in Tabel 2 identiek is (zie de zooappellativa hond-pes, vogel-pták, kat-kočka, vis-ryba, beer-medvěd, aap-opice, leeuw-lev, paard-kůn̆, slang - had, vos - liška, lam - beránek, varken - prase, kreeft - rak), tonen de registers van de meest gebruikte zoonyma in de Nederlandse en in de Tsjechische vaste adjectivische vergelijkingen enkele verschillen aan. We moeten er bijv. rekening mee houden, dat de vaak voorkomende benamingen van dieren in beide talen niet altijd met dezelfde eigenschappen worden geassocieerd - verg. de bijvoeglijke naamwoorden, die bijv. bij de Nederlandse en Tsjechische zooappellativa aap opice, kat - kočka, ${ }^{13}$ hond - pes of paard - kůn̆ worden genoemd.

Het verschil in de frequentie van de zooappellativa kan geïllustreerd woorden o.a. met de in het Nederlands tamelijk vaak voorkomende comparata pauw, ezel en aal. Deze benamingen van dieren verschijnen ook in de Tsjechische vaste vergelijkingen en worden met dezelfde eigenschappen geassocieerd, maar in het Tsjechisch komen ze niet voor in de groep van twintig vaakst gebruikte zooppellativa in adjectivische vergelijkingen. Het in het Tsjechisch vaak voorkomende

${ }^{13}$ Katten worden in het Tsjechisch positiever waargenomen dan in het Nederlands. 
zooappellativum blecha (vlo) verschijnt in de Nederlandse vergelijkingen helemaal niet, aan de andere kant ontbreken in de Tsjechische adjectivische vergelijkingen de in het Nederlands vaak gebruikte zooappellativa pier en garnaal.

Een heel vaak gebruikte comparator in de Tsjechische adjectivische vergelijkingen is het woord prase (varken). In enkele van de in het Tsjechische corpus SYN versie 5 gevonden voorbeelden gaat het echter niet om een echte vergelijking (Mrhačová \& Kouptsevitch 2004: 158). De constructies jako prase (als een varken), eventueel jako sviňa (als een zwijn), jako pes (als een hond) of jako kráva (als een koe) worden in het Tsjechisch heel vaak gebruikt om een hoge graad van een eigenschap of van een kwaliteit expressief uit te drukken. Dit is het geval bijv. bij:

(v)ožralý jako prase/jako kráva (dronken/zat als een varken/als een koe)

rychlý jako prase (snel als een varken)

nachlazený jako prase (verkouden als een varken)

drahý jako sviňa (duur als een zwijn)

velký jako kráva/prase (groot als een koe/als een varken)

těžký jako kráva (zwaar als een koe)

Vaste vergelijkingen met deze zooappellativa worden in het Tsjechisch meestal als pejoratieven beschouwd. ${ }^{14}$ Nederlandse benamingen van dieren worden op deze manier echter meestal niet gebruikt.

Vaak zijn de vaste adjectivische vergelijkingen in beide talen gebaseerd op de gelijkenis (menselijke eigenschappen worden vergeleken met de eigenschappen van dieren), verg.:

vrij als een vogel - volný jako pták

zo traag als een slak/een schildpad - pomalýjako šnek/želva

zo rood als een kreeft - rudý jako rak

gehoorzaam als een hond-poslušný jako pes

Enkele vaste adjectivische vergelijkingen zijn gebaseerd niet op de gelijkenis, maar op de personificatie - de oorspronkelijk menselijke eigenschappen werden aan verschillende dieren toegewezen (verg. Mrhačová \& Kouptsevitch 2004: 157):

trots als een pauw - pyšný jako páv

zo listig als een slang - lstivý jako had

koppig als een ezel-tvrdohlavý jako mezek

zo arm als een kerkrat - chudý jako kostelní myš

Er bestaat ook een kleine groep vaste adjectivische vergelijkingen met benamingen van dieren, die in het Tsjechisch en in het Nederlands hetzelfde tertium comparationis hebben, maar die zich in het gebruikte zooappellativum verschillen. Dit is het geval bijv. bij:

(zo) fris als een hoentje - svěži/čilý jako rybička (fris als een visje)

(zo) bang als een wezel - bázlivý jak zajic (bang als een haas)

grijs als een duif-šedý jako myš (grijs als een muis)

${ }^{14}$ Zulke pejoratieve vergelijkingen worden heel vaak in het gesproken Tsjechisch gebruikt. 
In enkele gevallen kent het Tsjechisch dezelfde vaste adjectivische vergelijking met een zooappellativum zoals het Nederlands, maar toch wordt er volgens de gegevens uit het Tsjechische corpus SYN versie 5 voorkeur gegeven aan een vergelijking zonder zooppellativum, verg. hluchý jako poleno/pařez/tetřev (doof als een blok/stronk/korhoen) - doof als een kwartel. ${ }^{15}$

Aan de andere kant zijn er ook gevallen te vinden waar in het Tsjechisch een vergelijking met een zooappellativum staat terwijl in het Nederlands meestal een vergelijking zonder zooappelativum wordt gebruikt, bijv. slabý jako moucha (zwak/slap als een vlieg) - slap als een vatdoek, štastný jako blecha (gelukkig als een vlo) ${ }^{16}$ - gelukkig/blij als een kind.

\section{Conclusie}

Het doel van ons onderzoek was om de registers van de frequentste zooappellativa te vergelijken die als comparata in vaste adjectivische vergelijkingen in het hedendaags geschreven Nederlands en in het hedendaags geschreven Tsjechisch gebruikt worden. We zijn uitgegaan van de veronderstelling dat het Nederlands en het Tsjechisch over enkele gelijke vaste adjectivische vergelijkingen met hetzelfde dierelement beschikken, maar dat de frequentie van deze congruente vaste vergelijkingen mogelijk verschillend kan zijn. Op grond van het corpusonderzoek hebben we deze hypothese kunnen verifiëren. Daarnaast konden we de volgende overeenkomsten en verschillen vaststellen.

De registers van de frequentste zooappellativa in vaste adjectivische komen grotendeels overeen. Toch zijn er in beide talen benamingen van dieren te vinden die in de andere taal als comparata niet gebruikt worden of een aanzienlijk hogere of juist lagere gebruiksfrequentie vertonen. Volgens de gegevens uit het Corpus Hedendaags Nederlands en het Tsjechische corpus SYN versie 5 worden sommige zooappellativa in het Nederlands bovendien met andere eigenschappen geassocieerd dan in het Tsjechisch.

Als onderdeel van de vaak gebruikte Tsjechische en Nederlandse vaste adjectivische vergelijkingen komen niet uitsluitend gedomesticeerde dieren voor - er verschijnen hier ook wilde en exotische dieren. Hiernaast lijkt het, dat insecten in de Tsjechische vergelijkingen in grotere mate vertegenwoordigd worden, terwijl vogels en waterdieren een belangrijkere rol in het Nederlands spelen. Een deel van de Tsjechische adjectivische vergelijkingen met benamingen van enkele ge-

15 Het zooappelativum kwartel - křepelka wordt in het Tsjechisch in positieve contexten gebruikt: být (čilý) jako křepelka (levendig als een kwartel zijn), běhat jako křepelka (lopen als een kwartel), dwz. levendig en gezond zijn/lopen - verg. Čermák et al. (2009: 178).

${ }^{16}$ In het Tsjechisch bestaat de vergelijking štastný jako ditě (gelukkig als een kind), maar die is niet zo frequent als de vergelijking met het comparatum blecha (vlo). 
domesticeerde dieren is bovendien zeer expressief en dient voor het uitdrukken van een hoge graad van een eigenschap of een kwaliteit.

In het algemeen worden er in de Tsjechische vaste adjectivische vergelijkingen meer zooappellativa gebruikt dan in de Nederlandse vergelijkingen. In het Tsjechisch vormen vaste adjectivische vergelijkingen met een dierelement ook vaker synoniemenrijen.

\section{Bibliografie}

Buršíková, Kristýna (2006): Equivalentie van fraseologismen met kat of/en hond in het Tsjechisch en het Nederlands. (Niet gepubliceerde masterscriptie.) FF UK Praha.

Corpus Hedendaags Nederlands, laatst geraadpleegd op: 12.06 .2017 (http://chn.inl.nl/).

Čermák, František e.a. (2009): Slovník české frazeologie a idiomatiky 1. Přirovnání. Praha: Karolinum.

Groot, Hans de e.a. (1999): Idioomwoordenboek. Verklaring en herkomst van uitdrukkingen en gezegden. Utrecht/Antwerpen: Van Dale Lexicografie, Amsterdam/Brussel: Reader's Digest.

Korpus SYN, versie 5. Ústav Českého národního korpusu FF UK, Praha 2017, laatst geraadpleegd op: 4.06.2017 (http://www.korpus.cz).

Kowalska-Szubert, Agata (1996): De kool en de geit. Nederlandse vaste verbindingen met een dieren plantelement. Utrecht: Led.

Krátká, Kateřina (2008): Vergelijkingen met een dierelement in het Nederlands en in het Tsjechisch. (Niet gepubliceerde bachelorscriptie). FF UP Olomouc.

Mrhačová, Eva e.a. (2000): Pojmenování zvířat v české a německé frazeologii a idiomatice. Českonèmecký slovnik. Tierbezeichnungen in der deutschen und tschechischen Phraseologie und Idiomatik. Deutsch-tschechisches Wörterbuch. Ostrava: Universum.

Mrhačová, Eva \& Kouptsevitch, Olena (2004): “Ustálená přirovnání se zooapelativem jako bázovým slovem v současné češtině, polštině, ruštině a ukrajinštině”. In: Eslavistica Complutense, nr. 4, Madrid: Universidad Complutense, 153-163.

Mgr. Kateřina Křížová, Ph.D. (*1975) studeerde Tsjechisch, Duits en Nederlands aan de Univerzita Palackého in Olomouc. Na haar studie was zij als lectrice verantwoordelijk voor het onderwijs Tsjechisch aan de Universiteit Gent. Zij promoveerde in 2005 te Olomouc op een vergelijking van Tsjechische, Duitse en Nederlandse fraseologie. Momenteel werkt ze als taalkundige bij de vakgroep neerlandistiek in Olomouc. Haar interesse gaat uit naar de comparatieve taalkunde, lexicologie en fraseologismen in het Nederlands en Tsjechisch in vergelijking.

e-mail: katerina.krizova@upol.cz,kamalkova@hotmail.com

Neerlandica Wratislaviensia 27, 2017

(C) for this edition by CNS 